\title{
Ensuring the Environmental and Industrial Safety in Solid Mineral Deposit Surface Mining
}

\author{
Kliment Trubetskoy ${ }^{1}$, Marina Rylnikova ${ }^{1 *}$, and Ekaterina Esina ${ }^{1}$ \\ ${ }^{1}$ Federal State-Funded Research Establishment - Academician N.V. Melnikov Institute of \\ Comprehensive Exploitation of Mineral Resources, Russian Academy of Sciences (IPKON RAS) \\ 111020, 4 Kryukovsky tupik, Moscow, Russia
}

\begin{abstract}
The growing environmental pressure of mineral deposit surface mining and severization of industrial safety requirements dictate the necessity of refining the regulatory framework governing safe and efficient development of underground resources. The applicable regulatory documentation governing the procedure of ore open-pit wall and bench stability design for the stage of pit reaching its final boundary was issued several decades ago. Over recent decades, mining and geomechanical conditions have changed significantly in surface mining operations, numerous new software packages and computer developments have appeared, opportunities of experimental methods of source data collection and processing, grounding of the permissible parameters of open pit walls have changed dramatically, and, thus, methods of risk assessment have been perfected [10-13]. IPKON RAS, with the support of the Federal Service for Environmental Supervision, assumed the role of the initiator of the project for the development of Federal norms and regulations of industrial safety "Rules for ensuring the stability of walls and benches of open pits, open-cast mines and spoil banks", which contribute to the improvement of economic efficiency and safety of mineral deposit surface mining and enhancement of the competitiveness of Russian mines at the international level that is very important in the current situation.
\end{abstract}

\section{Introduction}

Less favorable geological and mining conditions of mineral deposits being developed and some deposits planned for mining, ever growing ore and fuel demand dictate the necessity of refining the existing regulatory framework with due account for the commercialization of novel geotechnologies to enhance the efficiency of mining and minimize the environmental pressure.

\section{Materials and methods}

In conditions of mineral reserves mining at deeper horizons a top-priority area of environmental and industrial safety and enhanced efficiency of mining processes involves

\footnotetext{
* Corresponding author: rylnikova@mail.ru
} 
the development of robotized geotechnologies eliminating the human presence in danger zones of mining operations. For instance, the employment of a self-driving intelligent dump truck operating in an autonomous mode can significantly expand the area of the efficient surface mining application with radical upgrading of an open-pit infrastructure.

In this case, the requirements to open-pit roads are updated, including the provision of the relevant quality of the road surface, as for the application of robotized transport technologies the motor road irregularities, fast turns and other open-pit road quality deviations from standard values may results in the changing of the path of transport machinery travel that will eventually affect the open-pit safety-in-operation. Main criteria of road surface quality assessment are as follows: pavement strength, smoothness, hardness, tires' grip on the road surface.

Application of an autonomous automated dump truck with intelligent control can minimize or completely eliminate the human factor effect on the performance of operational processes. In this case, intelligent functions of mine engineers and managers increase, values of open-pit main parameters, some structural elements of the mining system, first of all the height and slope angle of working benches, change qualitatively, thus significantly enhancing the economic and ecological efficiency of surface mining operations [1-4].

Application of robotized mining and transport machinery provides an opportunity of more complete mining of mineral reserves, which earlier were not included in the planned final pit envelope. In providing the rationale for a new final pit envelope the width of a bench is determined only by the performance capabilities and parameters of the equipment with due account for non-presence of the personnel directly in a face. As robotized equipment is furnished with sensors monitoring the space position of working elements and the machinery itself with due account for the requirements to the minimal width of a bench it is important to proceed from the minimal dimensions and off-contact clearance providing for safe operation of the process equipment.

Studies of IPKON RAS performed in cooperation with VIST Group have proved that application of robotized machinery allows significant reduction of the bench width and thus the increase of the open-pit depth for final extraction of reserves occurring below its planned final boundary [5-8]. With robotized machinery, due to non-presence of the personnel in the face it is possible to minimize the values of some parameters and to eliminate some elements of the open-pit design as a mining structure, which are intended for safety-in-mining, as compared with similar conditions, however envisaging the presence of miners in a working zone.

Furthermore, one of the promising areas of mining efficiency enhancement is the development of inclined and steeply dipping ore and coal beds with the use of high overburden benches. High benches are seen as benches with a common slope plane, which parameters exceed the potential of loading and haulage machinery, and these benches are developed by hole blasting for the full height and mined by separate layers - sub-benches. A sub-bench height is determined by the potential of excavation and loading machinery.

The increase of an overburden bench full height provides a perfect logistic pattern of an ore open pit and allows the minimization of the total number of open-pit transportation machinery, with that, the time of machinery and equipment running, number of working benches, length of transportation routes and number of dumping points are minimized, while the effective depth of surface mining operations increases. All items listed above minimize the negative environmental effect of surface mining.

It has been proved that a high overburden bench is feasibly developed in two layers [9]. As a result of assessment of the efficiency of different high overburden bench mining scenarios it has been found that the most advantageous mining method is the one employing an excavation and loading system consisting of a downward-digging excavator 
(dragline type) located at the upper site of a bench and excavating the upper layer, with the material loading at the level of its location, and a face shovel excavating the lower layer, with the mined material loading onto the lower transport level (fig. 1).

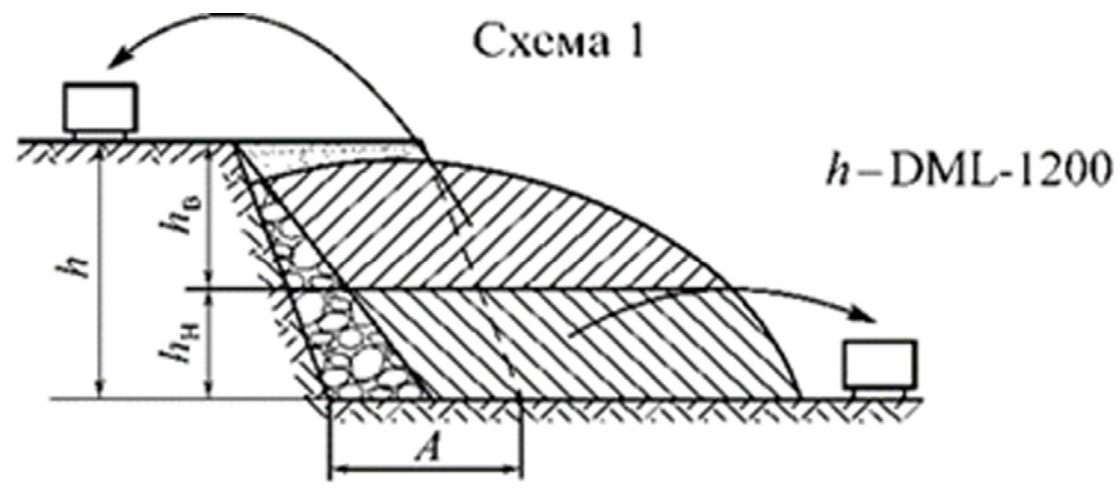

Fig. 1 - High overburden bench development in two layers with ESh-10.70 (ESh-14.50) excavator for the upper sub-bench and EKG-10 face shovel for the lower sub-bench development: $h_{\mathrm{H}}$ and $h_{\mathrm{B}}-$ height of upper and lower layers accordingly, $\mathrm{m} ; A$ - height of drilling and blasting cut, $\mathrm{m}$.

It has been proved that the highest extension of reserves to be developed due to greater open-pit depth is provided by the transition to high overburden benches at the moment of achieving the equivalence of the current and boundary overburden ratio - at the stage of the maximum development of mining operations. According to the principle of assessment of the final depth of surface mining operations by the equivalence of the boundary and current overburden ratio, pit walls have slope angles equal to those of working benches, and the open-pit width increases until the current overburden ratio reaches the boundary value, i.e., until the moment of the maximum development of surface mining operations. Further development of mining operations with the working bench slope angle being maintained at a base planned level is not economically feasible. In this case the volume of overburden removed at a later stage is minimized.

It is evident that the above described innovations and some other surface geotechnologies, new mining and transport machinery eliminating the need of operator's presence in unfavorable conditions of the open-pit working zone change the requirements to the level of risk and dictate the necessity of refining the regulatory and procedural framework governing the efficient and safe development of solid mineral deposits.

\section{Results and discussion}

The currently applicable regulatory documentation governing the procedure of ore open-pit wall and bench stability design for the stage of pit reaching its final boundary was issued several decades ago. Moreover, the status of applicable document is granted only to the "Rules for ensuring the stability of slopes at coal opencast mines" of 1998, while outside the coal sector the status of this document is in question.

Over recent decades, mining and geomechanical conditions have changed significantly in surface mining operations, numerous new software packages and computer developments have appeared, opportunities of experimental methods of source data collection and processing, grounding of the permissible parameters of open pit walls have changed dramatically, and, thus, methods of risk assessment have been perfected [10-13]. The necessity is ever growing of implementing the projects meeting the international standards [14-16]. Imperfection, and in some cases, lack of the applicable regulatory 
framework create unjustified difficulties in the preparation of design documentation for mineral deposit development, as well as its audit and review.

A number of mining companies, design and research establishments, experts of the Federal Service for Environmental, Technological, and Nuclear Supervision have recognized the fact that at the present moment there is a pressing need of elaborating a new regulatory document on geomechanical substantiation and provision of pit wall and bench stability, in which not only the full scope of accumulated Russian and foreign practices of such substantiation will be utilized and the legitimate framework of design and calculation methods will be expanded, but methodological approaches making easier the interaction of mineral developers, license holders, production personnel, researchers, designers and experts will be also determined.

In that context the elaboration of Federal norms and regulations of industrial safety "Rules for ensuring the stability of walls and benches of open pits, open-cast mines and spoil banks" (FNR), facilitating the enhancement of economic efficiency and safety of mineral deposit surface mining, as well as the competitiveness of Russian mines at the international level is very important in the current situation.

The necessity of elaborating the FNR is predetermined by the following factors:

- advent of qualitatively new methods of engineering-geological assessment of the rock mass;

- necessity of giving due account to the existing tectonic stresses and bulk forces caused by the slope curvature in plan;

- expansion of the application area of mineral deposit combined mining method;

- advent of new computational tools and slope stability design methods;

- removal of severe constraints for bench height and safety berm width at the stage of reaching the final pit boundary that allows higher angles of pit wall recovery;

- advent of new surface geotechnologies and novel mining and transport machinery, which operation eliminates the necessity of operator's presence in the working area of an open pit and changes the requirements to the risk level;

- advent of new methods of the rock mass state monitoring and control;

significant difference between Russian and international norms and standards of slope stability design rationale;

- greater dependence of mine economics on the angle of safe slopes and overburden ratio in case of large-scale production;

- severization of the requirements of the General Board of State Expert Review to engineering design freezing in compliance with the country's applicable legislation.

By the decision of the Federal Service for Environmental, Technological, and Nuclear Supervision the elaboration of norms and regulations "Rules for ensuring the stability of walls and benches of open pits, open-cast mines and spoil banks" was assigned to the Academician N.V. Melnikov Institute of Comprehensive Exploitation of Mineral Resources of the Russian Academy of Sciences. It is evident that the elaboration of this large and important regulatory and procedural document can be implemented only on condition of joining and coordination of efforts of all experts in this area. A megaproject "Ensuring the stability of slopes in surface mining" was launched for the preparation of the FNR. The main objective of this project is the elaboration of the regulatory documentation putting into law the rules ensuring pit wall and bench and spoil bank slope stability specified in accordance with the established procedure and giving due account for the accumulated practices and achievements of the mining science oriented towards an opportunity of application of novel developing geotechnologies.

Project tasks:

- customization of norms ensuring the slope stability in line with the current conditions of surface mining, methods of the rock mass state assessment and control; 
- synchronization of the applicable Russian norms of ensuring the slope stability with the international practice;

- utmost full utilization of the potential of modern means, methods and technologies for ensuring the slope stability and enhancing the efficiency of surface mining operations;

- removal of the barriers and provision of an opportunity of novel technology implementation in mining projects;

- enhancement of the efficiency of surface mine operation in the Russia's legal framework of mineral resources management;

- taking into account the interests of mineral developers in the enhancement of the efficiency and safety-in-mining.

In the process of the FNR preparation the requirements and recommendations will be classified by type of mined minerals, and due account will be given to an opportunity of developing and updating of all supplements to the FNR in a certain period of time.

\section{Conclusions}

Application of robotized machinery in solid mineral deposit surface mining provides an opportunity of the maximum improvement of mining and transport equipment performance due to minimization of time expenditure for mining and mined material transportation processes, and elimination of the human factor effect on the performance of operational processes. Application of intelligent machinery, due to the non-presence of the personnel in a face opens an opportunity of minimizing the values of some parameters and eliminating some elements of an open-pit design as a mining structure, in compliance with safe working practices in mining.

Application of high overburden benches in surface mining of inclined and steeply dipping deposits provides higher recovery ratio of deposit reserves with higher efficiency of surface mining and minimized environmental effect.

Commercialization of novel technologies of solid mineral deposit development dictates the necessity of refining the regulatory and procedural framework governing the efficient and safe development of mineral deposits. Basically, the megaproject "Ensuring the stability of slopes in surface mining" is aimed at the solution of all these tasks.

The studies have been performed with the support of the Russian Science Foundation, Project No 14-37-00050

\section{References}

1. C. Brown, Autonomous Mining, 1, 30 (2012)

2. S. Arvidsson, Géosciences, 1, 64 (2005)

3. E. Nebot Robotics Research, 28, 268 (2007)

4. J.J. Green, K. Hlophe, J. Dickens, R. Teleka, M. Price International Journal of Engineering and Advanced Technology, 1:4, 8 (2012)

5. K. N. Trubetskoy, D.R. Kaplunov, M.V. Rylnikova Journal of Mining Science, 48:4 688 (2012)

6. K.N. Trubetskoy, D.J. Vladimirov, I.A. Pytalev, T.M. Popova, Mining magazine, 5, 21 (2016)

7. M.V. Rylnikova, D.J. Vladimirov, I.A. Pytalev, T.M. Popova, Journal of Mining Science, 1, 92 (2017)

8. K. N., Trubetskoy, Mining Journal, 7, 4 (2013)

9. V.A. Kovalev, V.S. Fedotenko, Journal of Mining Science, 51:5, 865 (2015)

10. C. O. Brawner, Mining Engineering, 38:8, 823 (1986) 
11. R. Thompson, S. Hahn, S. Pastor, Mining Engineering, 67:9, 34 (2015)

12. H. Tonderai Chiwaye, A comparison of the limit equilibrium and numerical modeling approaches to risk analysis for open pit mine slopes: Dissertation for to degree of Master of Science in Engineering (University of the Witwatersrand, 2010)

13. E. Hoek, C. Caranza-Torres, B. Corcum, Proceedings of the North American Rock Mechanics Society. Mining Innovation and Technology, (2002)

14. J. Read, P. Stacey, Guidelines for Open pit slope design (CSIRO 2009)

15. G. Beale and J. Read Guidelines for Evaluating Water in Pit Slope Stability (CSIRO, 2013)

16. E. Hormazabal, F. Rovira, El Teniente mine in Chile, 1 (2009) 